\title{
PYROLYSIS AND ACID HYDROLYSIS OF LIGNOCELLULOSIC BIOMASS AS A TOOL FOR MONOSACCHARIDE OBTAINING
}

\author{
*Daniela Godina ${ }^{1,2}$, Ralfs Pomilovskis ${ }^{1}$, Nadezda Iljinaa ${ }^{1,2}$, Kristine Meile ${ }^{1}$, Aivars Zhurinsh ${ }^{1}$ \\ ${ }^{1}$ Latvian State Institute of Wood Chemistry, Latvia \\ ${ }^{2}$ University of Latvia, Latvia \\ *Corresponding author's email: danielagodina393@gmail.com
}

\begin{abstract}
Due to the ever increasing demand for energy resources, more and more attention is being paid to renewable energy resources. One such potential resource is lignocellulosic biomass that can be treated to acquire a carbohydrate rich substrate for further use in producing biofuels such as bioethanol or biobutanol. In this study, birch (Betula pendula) chips were used in fast pyrolysis to acquire bio-oil. This bio-oil was further hydrolyzed in pressurized reactor Parr 4554 to produce a carbohydrate rich feedstock. Hydrolysis conditions were optimized. Several conditions - three different temperatures $\left(111,121,131^{\circ} \mathrm{C}\right)$ and four different sulfuric acid concentrations $(0.05,0.1,0.2,0.5 \mathrm{M})$ were tested. The optimal conditions were $121{ }^{\circ} \mathrm{C}$ with $0.2 \mathrm{M}$ sulfuric acid as a catalyst that allowed to acquire a solution with the total glucose concentration being $6.6 \%$ that can be further used as a feedstock for biofuel acquiring.
\end{abstract}

Key words: acid hydrolysis, lignocellulose, biomass, bio-oil, levoglucosan, glucose.

\section{Introduction}

Nowadays, more and more attention is being paid to efficient use of feedstock of biological origin, to produce a wide range of products, from bulk chemicals to highly specialized refined building blocks, in integrated biorefinery concept (Huber, Iborra, \& Corma, 2006; Mohan, Pittman, \& Steele, 2006). Due to its relatively low cost, wide availability and renewability, lignocellulosic biomass is being extensively studied as a feedstock for production of various platform chemicals as well as energetic resource production (Isikgor \& Becer, 2015). In Latvia, one of the most promising lignocellulosic biomass sources is the forestry industry that in addition to targeted products also produces a significant amount of wastage in the form of sawdust, chips, bark, etc. (LR Zemkopības Ministrija, 2018).

Lignocellulosic biomass is mostly composed of three different polymeric compounds. The first is lignin which is a complex macro-molecule mostly made up of different phenyl propane units (p-coumaryl alcohol, coniferyl alcohol, and sinapyl alcohol) (Schuler et al., 2019). Hemicellulose is an amorphous carbohydrate composed of various hexoses and pentoses, mostly glucose, galactose, mannose, arabinose and xylose (Bennett, Helle, \& Duff, 2009). Cellulose is composed of glucose sub-units making long ordered fibers with high crystallinity (Ragauskas et al., 2006).
To convert lignocellulosic biomass into fuel, the first step inevitably must be the deconstruction of the solid lignocellulosic material into smaller intermediates that can be further used as building blocks for fuels and chemicals (Huber et al., 2005; Aden et al., 2002; Mohan, Pittman, \& Steele, 2006). There are two main pathways for degradation of lignocellulosic biomass. The first is hydrolysis using either acids or enzymes (Mosier et al., 2005). The second is thermal treatment, most commonly it being fast pyrolysis (Lian et al., 2010; Mettler et al., 2012; Czernik \& Bridgwater, 2004; Helle et al., 2007). Fast pyrolysis is one of the most interesting pathways for lignocellulosic biomass processing (Sipilä et al., 1998; Oasmaa \& Czernik, 1999). It allows to obtain bio-oil which is a complex mixture of various industry-significant chemicals like furfural, 5-hydroxymethylfurfural, various acids, monomeric carbohydrates, anhydro-sugars as well as bigger carbohydrate fragments and phenolic glucosides (Bridgwater, 1999). One important product of fast pyrolysis is levoglucosan (LG) which can easily be obtained and separated from the fast pyrolysis liquor as described previously by us (Meile \& Zhurinsh, 2016).

Since levoglucosan is an anhydrosugar, it can be quite easily hydrolyzed using acidic medium (Figure 1) (Bennett, Helle, \& Duff, 2009). Levoglucosan hydrolysis is a first-rate reaction
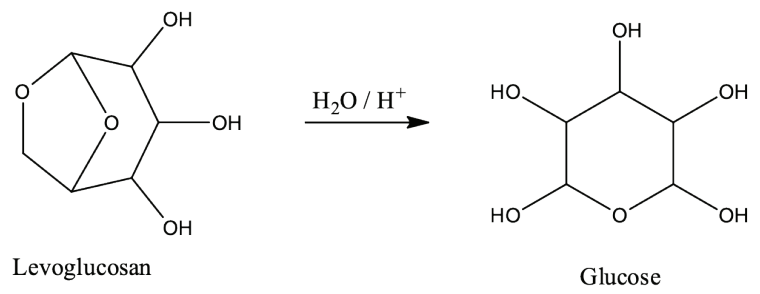

Figure 1. Levoglucosan acid hydrolysis scheme. 
since in water medium water concentration remains constant and the reaction rate is dependent only of the levoglucosan concentration (Helle et al., 2007). Also, this acquired bio-oil contains various phenyl glucoside type compounds that can also be hydrolyzed to release free glucose into solution. By combining fast pyrolysis and acid hydrolysis of lignocellulosic biomass it is possible to obtain a solution with a high concentration of monosaccharides that can be further used as a feedstock for production of biofuels, either bioethanol or biobutanol. In this work novel approach, incorporating both fast pyrolysis and acid hydrolysis, is being tested to produce carbohydrate rich feedstock, from lignocellulosic biomass, suitable for application of bio-fuel obtaining. The aim of this work was to obtain feedstock with a high concentration of monosaccharides that can be used as a feedstock for bio-fuel obtaining.

\section{Materials and Methods}

Materials and chemicals

Levoglucosan (99\%), glucose (99\%) and sulfuric acid (95-97\%) were purchased from Merck and used without further purification. For HPLC analysis Millipore deionized water was used. All samples were filtered through Kinesis nylon syringe filters $(0.22 \mu \mathrm{m})$ before HPLC analysis.

Samples

The condensable pyrolysis products were obtained at LSIWC. Birch (Betula pendula) chips were treated with diluted sulfuric acid (2\% of oven dry wood mass) and washed with deionized water. The obtained lignocellulose was ground to particle size $<2 \mathrm{~mm}$. The lignocellulose was pyrolyzed in a superheated steam $\left(380-420^{\circ} \mathrm{C}\right)$ flow in an entrained flow thermoreactor, after which char was separated in a cyclone, but the liquid products in a condenser.

Pyrolysis liquid sample acid hydrolysis

Anhydro and oligomeric sugars in the fast pyrolysis bio-oil were hydrolyzed in pressurized reactor Parr 4554 with $\mathrm{H}_{2} \mathrm{SO}_{4}$ at 3 different temperatures $(111 ; 121$; $\left.131^{\circ} \mathrm{C}\right)$ and 4 different acid concentrations $(0.05,0.1$, $0.2,0.5 \mathrm{M}$ ). For each acid hydrolysis was conducted one parallel experiment. First sample was collected when the temperature in the reactor reached $100{ }^{\circ} \mathrm{C}$, then next sample was collected when set temperature was reached and further with interval of 5 minutes between samples. In total 9 samples were collected per reaction. Since the time to reach the set temperature is different, the total reaction time is different as well for each hydrolysis temperature.

Theoretical glucose content was calculated by Eq. 1.

$$
W_{G L C, \text { calc }}=W_{G L C, 0}+\frac{M_{G L C}}{M_{L G}}
$$

\section{HPLC analysis}

Qualitative and quantitative measurements of C5 and C6 sugars were done using High Performance Liquid Chromatography Equipment with Column Thermostat, quaternary gradient pump with mobile phase degasification and refractive Index Detector (RI) (ECOM, Czech Republic). For the separation of LG and glucose HPLC Sugar SP0810 column (7 $\mu \mathrm{m}, 8 \mathrm{~mm} \times 300 \mathrm{~mm}$ ) (Shodex, Japan) was used. The column temperature was $80{ }^{\circ} \mathrm{C}$ and the mobile phase was Millipore deionized water (Direct - Q 3UV $18.2 \mathrm{M} \Omega \cdot \mathrm{cm}^{-1} 25^{\circ} \mathrm{C}$ ) with flow rate $0.5 \mathrm{~mL} \cdot \mathrm{min}^{-1}$. Injection volume was $20 \mu \mathrm{L}$. Refractive index detector cell temperature was $55^{\circ} \mathrm{C}$.

Hydrolyzed pyrolysis liquid samples were neutralized with barium carbonate for $24 \mathrm{~h}$, then diluted with deionized water and filtered through Kinesis nylon syringe filters $(0.22 \mu \mathrm{m})$ before analysis.

Partial validation was performed in accordance to EuraChem method validation guidelines (Magnusson \& Örnemark, 2014). Tests were done to evaluate the repeatability and trueness of the optimal HPLC method with the Sugar SP0810 column. Repeatability was characterised by the relative standard deviation of six sample solution replicates. Trueness was characterised by the recovery of LG and glucose standard in hydrolyzed pyrolysis liquid samples spiked with 1.0 and $2.0 \mathrm{mg} \cdot \mathrm{mL}^{-1}$ of LG and glucose. Limit of detection (LOD) and limit of quantification (LOQ) was calculated based on the standard deviation (SD) of four standard solution measurements by Eq.2. and 3, respectively.

$$
\begin{aligned}
& L O D=\frac{3.3 \times S D}{\text { slope }} \\
& L O Q=\frac{10 \times S D}{\text { slope }}
\end{aligned}
$$

\section{Wet chemistry methods of analysis}

C6 total sugar content determination with iodometric titration.

To $0.1 \mathrm{~g}$ of the sample $0.2 \mathrm{~mL}$ of $15 \%$ sulfuric acid and $1 \mathrm{~mL}$ of $0.2 \mathrm{M}$ sodium periodate solution was added. These samples were heated at $40{ }^{\circ} \mathrm{C}$ for 4.5 hours. After that $5 \mathrm{~mL}$ of $10 \%$ ammonium molybdate was added. After $15 \mathrm{~min} 1 \mathrm{~mL}$ of acetic acid and $1 \mathrm{~mL}$ $10 \%$ potassium iodide was added. After $15 \mathrm{~min}$ the solution was tittered with $0.1 \mathrm{M}$ sodium thiosulfate in the presence of starch as an indicator.

Total aldehyde content determination.

To $2 \mathrm{~mL}$ of the sample $5 \mathrm{~mL}$ of $10 \%$ hydroxylamine solution was added. After 2.5 hours $20 \mathrm{~mL}$ of 2-propanol was added, and samples were titrated with $0.1 \mathrm{M} \mathrm{KOH}$ solution.

Sulfuric acid determination.

To $1 \mathrm{~mL}$ of the sample $\sim 20 \mathrm{~mL}$ of deionized water was added, and the sample was titrated with $0.1 \mathrm{M}$ $\mathrm{KOH}$ solution. 
Total solid residue determination.

About $15 \mathrm{~mL}$ of the sample was weighted, and the sample was heated at $103{ }^{\circ} \mathrm{C}$ until constant mass was reached. The result was determined as the mass difference.

\section{Results and Discussion}

HPLC-RI analysis of hydrolyzed pyrolysis liquid samples

To determine levoglucosan and glucose concentration changes in the pyrolysis liquid sample during acid hydrolysis process, an HPLC-RI method was developed using Shodex Sugar SP0810 column as well as partially validated. Repeatability expressed as relative standard deviation for LG was $9 \%$ but for glucose was $5 \%$. Trueness was evaluated at two different levels done in triplicate. When the sample was spiked with $1.0 \mathrm{mg} \cdot \mathrm{mL}^{-1}$ of $\mathrm{LG}$ and glucose, the recovery of LG was $103.5 \%$ with standard deviation of $1.5 \%$, but for glucose $94.9 \%$ with standard deviation of $1.5 \%$, respectively. When the sample was spiked with $2.0 \mathrm{mg} \cdot \mathrm{mL}^{-1}$ of LG and glucose, the recovery of LG was $91 \%$ with standard deviation of $1 \%$, but for glucose $93.1 \%$ with standard deviation of

$1.2 \%$. Linearity was tested within the range from 0.2 to $15.0 \mathrm{mg} \cdot \mathrm{mL}^{-1}$.
The calculated LOD for levoglucosan was 0.07 $\mathrm{mg} \cdot \mathrm{mL}^{-1}$ and LOQ was $0.2 \mathrm{mg} \cdot \mathrm{mL}^{-1}$ but for glucose LOD was $0.04 \mathrm{mg} \cdot \mathrm{mL}^{-1}$ and LOQ $-0.11 \mathrm{mg} \cdot \mathrm{mL}^{-1}$.

Parameter optimization of pyrolysis liquid sample acid hydrolysis

Acid hydrolysis optimized parameters for pyrolysis liquid sample, were reaction temperature and the used sulfuric acid concentration.

Temperature optimization for acid hydrolysis.

Initially three different temperatures were tested $\left(111,121\right.$ and $\left.131^{\circ} \mathrm{C}\right)$, but the concentration of sulfuric acid catalyst in solution was $0.2 \mathrm{M}$. Wet chemistry methods of analysis of completely hydrolyzed samples shows (Table 1) that, when performing hydrolysis with increase of temperature, small increase of total hexose content can be observed that can be explained with hydrolysis of phenyl-glucoside type compounds. Aldehydes in solution with increased temperature undergoes condensation reactions leading to decrease in total aldehyde content.

According to the HPLC-RI data (Figure 2), the reaction rate of levoglucosan hydrolysis increases with the increase of temperature, with the highest rate at $131{ }^{\circ} \mathrm{C}$. At $11{ }^{\circ} \mathrm{C}$ hydrolysis rate of levoglucosan was $0.05 \% \cdot \mathrm{min}^{-1}$, at $121{ }^{\circ} \mathrm{C}$ it was $0.09 \% \cdot \mathrm{min}^{-1}$ but at $131{ }^{\circ} \mathrm{C}-0.16 \% \cdot \mathrm{min}^{-1}$. When comparing LG

Table 1

Characteristic parameters of hydrolyzed pyrolysis liquid sample at different hydrolysis temperatures (sulfuric acid concentration $-0.2 \mathrm{M}$ )

\begin{tabular}{|c|c|c|c|c|}
\hline Hydrolysis temperature, ${ }^{\circ} \mathrm{C}$ & Total hexoses, $\%$ & Total solids, $\%$ & Aldehydes, $\%$ & Sulfuric acid, $\%$ \\
\hline (initial sample) & 3.7 & 7.8 & 5.5 & 0.8 \\
\hline 111 & 6.6 & 7.4 & 5.3 & 2.4 \\
\hline 121 & 6.8 & 7.3 & 5.2 & 2.3 \\
\hline 131 & 7.0 & 7.3 & 5.0 & 2.5 \\
\hline
\end{tabular}

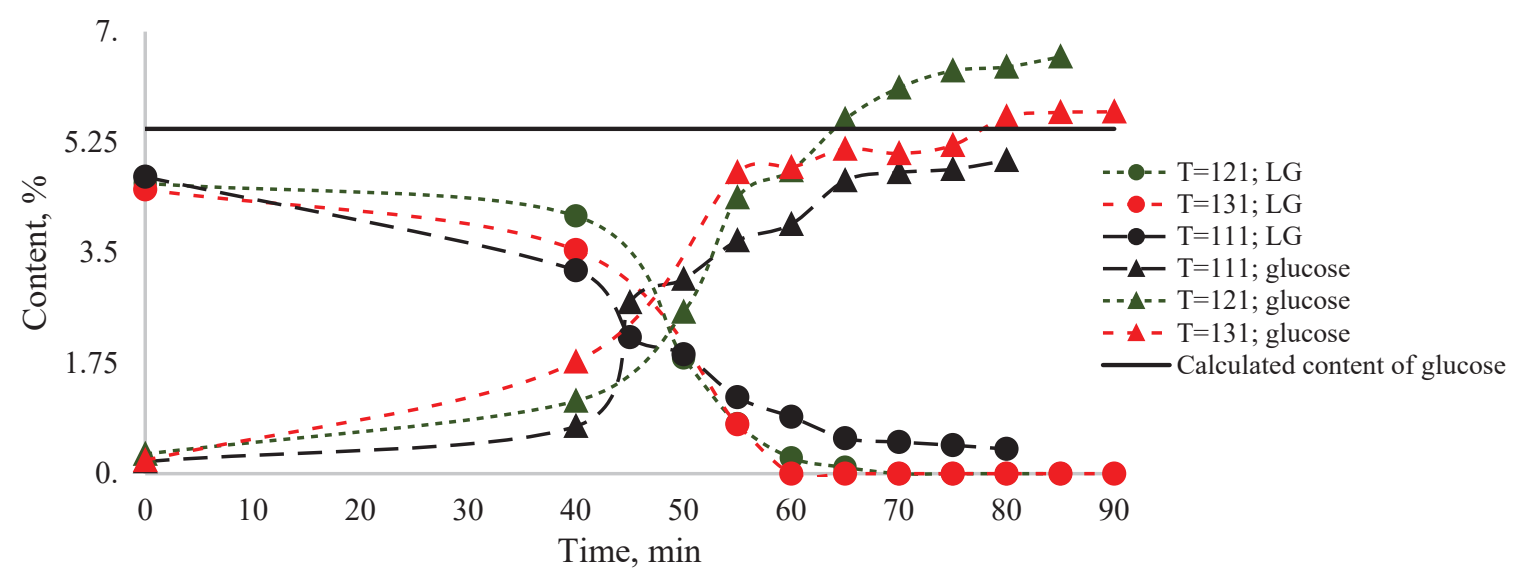

Figure 2. Levoglucosan and glucose content (\%) change in time during acid hydrolysis at different temperatures. 


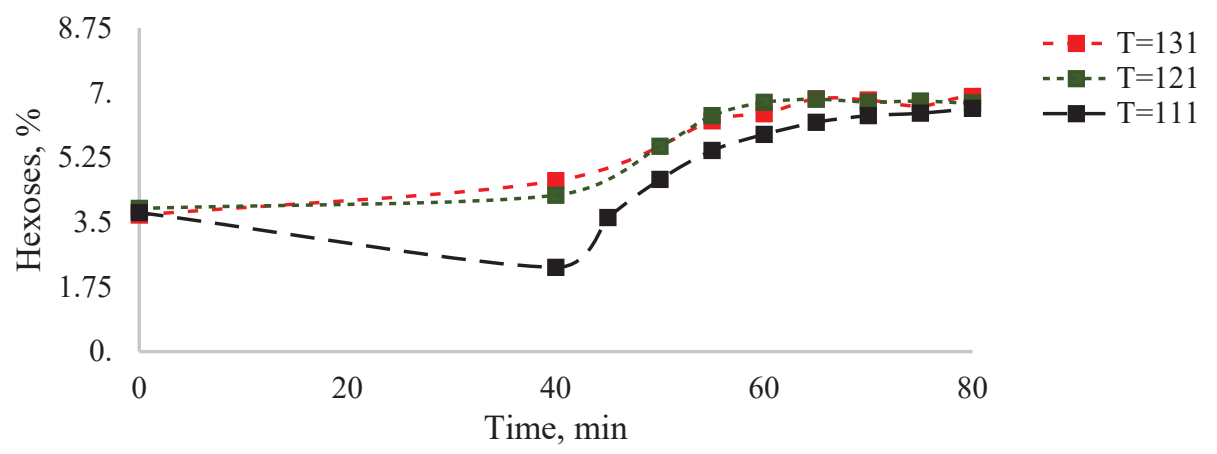

Figure 3. Total hexoses content (\%) change in time during acid hydrolysis at different temperatures.

content in relation to time, it is notable that at $111^{\circ} \mathrm{C}$ levoglucosan does not hydrolyse fully and reaches equilibrium at $0.4 \%$, but at both temperatures $121^{\circ} \mathrm{C}$ and $131{ }^{\circ} \mathrm{C}$ - after 60 minutes levoglucosan is fully hydrolyzed. After LG is fully hydrolysed, the glucose content continues to slowly increase. This can be observed both from HPLC results (Figure 2) and iodometric titration results (Figure 3). When comparing obtained results with calculated glucose content in solution taking into account starting concentrations of LG and glucose, it is apparent that obtained glucose concentration in solution exceeds calculated concentration. This indicates that in addition to LG there are other glucose containing compounds in solution that are being hydrolyzed. These are most likely various phenolic glucosides formed in fast pyrolysis process.

It must be said that although iodometric titration is a fast and widely used method for carbohydrate content determination, it can tend to overestimate results especially if there are reducing compounds present in the sample. Also, this method has bigger uncertainty which can make noticing small differences between samples impossible.

This allows to conclude that in the solution there are glucose containing compounds such as oligomeric carbohydrates or phenolic glucosides that are harder to hydrolyse than LG.

Taking into account these results, for the influence of catalyst content on hydrolysis process, two temperatures were tested -121 and $131^{\circ} \mathrm{C}$.
Hydrolysis of LG in water solution is a first-rate reaction and is dependent only on the concentration of LG, since the concentration of water remains unchanged for the duration of the reaction. When calculating the rate constants of levoglucosan hydrolysis using $0.2 \mathrm{M} \mathrm{H}_{2} \mathrm{SO}_{4}$ as catalyst, it was determined to be highly dependent on temperature increasing from $0.053 \mathrm{~min}^{-1}$ at $111{ }^{\circ} \mathrm{C}$ to $0.197 \mathrm{~min}^{-1}$ at $121{ }^{\circ} \mathrm{C}$. It was unable to determine the rate constant at $131^{\circ} \mathrm{C}$ since the reaction starts, and levoglucosan is partially hydrolyzed, before the temperature is reached.

Acid hydrolysis concentration optimization.

There are quite minor differences in the total hexose content with increased catalyst amount at $121^{\circ} \mathrm{C}$, but by increasing catalyst content from $0.05 \mathrm{M}$ to $0.5 \mathrm{M}$ there is a very prominent increase in the aldehyde concentration (Table 2). This aspect is noteworthy for further study, as increased aldehyde concentration can inhibit the rate at which biofuel is produced.

When comparing HPLC-RI obtained results at $121^{\circ} \mathrm{C}$, the highest amount of glucose in solution was reached by using $0.2 \mathrm{M}$ of sulfuric acid as catalyst (Figure 4). Increase of catalyst load to $0.5 M$ decreases the time in which the maximum glucose concentration is reached but does not further increase the glucose content.

When considering iodometric titration results content of total hexoses at the end of hydrolysis is practically the same between all concentrations of catalyst due to this method's limitation as described

\section{Characteristic parameters of completely hydrolyzed pyrolysis liquid sample using different} sulfuric acid concentrations at $121^{\circ} \mathrm{C}$

\begin{tabular}{|c|c|c|c|c|}
\hline Sulfuric acid concentration, $M$ & Total hexoses, $\%$ & Total solids, $\%$ & Aldehydes, $\%$ & Sulfuric acid, \% \\
\hline - (initial sample) & 3.7 & 7.8 & 5.5 & 0.8 \\
\hline 0.05 & 7.3 & 6.7 & 2.9 & 1.0 \\
\hline 0.2 & 6.8 & 7.3 & 5.2 & 2.3 \\
\hline 0.5 & 7.2 & 8.8 & 9.9 & 5.2 \\
\hline
\end{tabular}




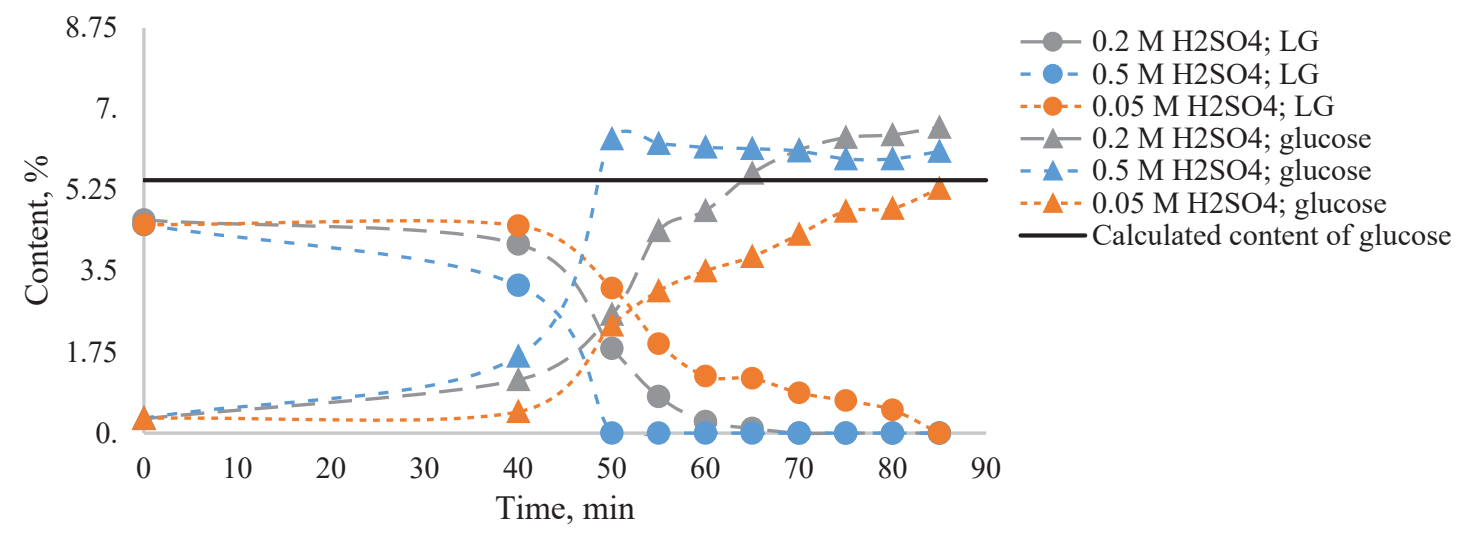

Figure 4. Levoglucosan and glucose content (\%) change in time during acid hydrolysis using different sulfuric acid concentrations at $121^{\circ} \mathrm{C}$.

previously (Figure 5). Similarly, as in HPLC-RI results, increased catalyst content decreases the time in which the total hexoses reach maximum but does not increase the total content at the end. Reaction rate constant at this temperature was $0.056 \mathrm{~min}^{-1}, 0.197$ $\mathrm{min}^{-1}$ and $0.204 \mathrm{~min}^{-1}$ using catalyst with $0.05 \mathrm{M} ; 0.2$ $M$ and $0.5 M$ concentration respectively. These results show that increasing the catalyst concentration beyond $0.2 M$ does not increase the rate of levoglucosan hydrolysis.

At $131{ }^{\circ} \mathrm{C}$, increase of catalyst concentration increases the total aldehyde concentration in the sample but does not increase the total hexoses content in the sample when hydrolysis is complete (Table 3 ).

At $131{ }^{\circ} \mathrm{C}$ best results were obtained using $0.2 \mathrm{M}$ sulfuric acid as catalyst with only minor differences between both catalyst concentrations (Figures 6, 7). When comparing conditions at both $121{ }^{\circ} \mathrm{C}$ and $131{ }^{\circ} \mathrm{C}$, using $0.2 M$ catalyst, it can be observed that at $131{ }^{\circ} \mathrm{C}$ there is a more pronounced increase in the glucose content after levoglucosan has fully hydrolyzed. Reaction rate constant for levoglucosan hydrolysis at $131{ }^{\circ} \mathrm{C}$ was detected to be $0.224 \mathrm{~min}^{-1}$.

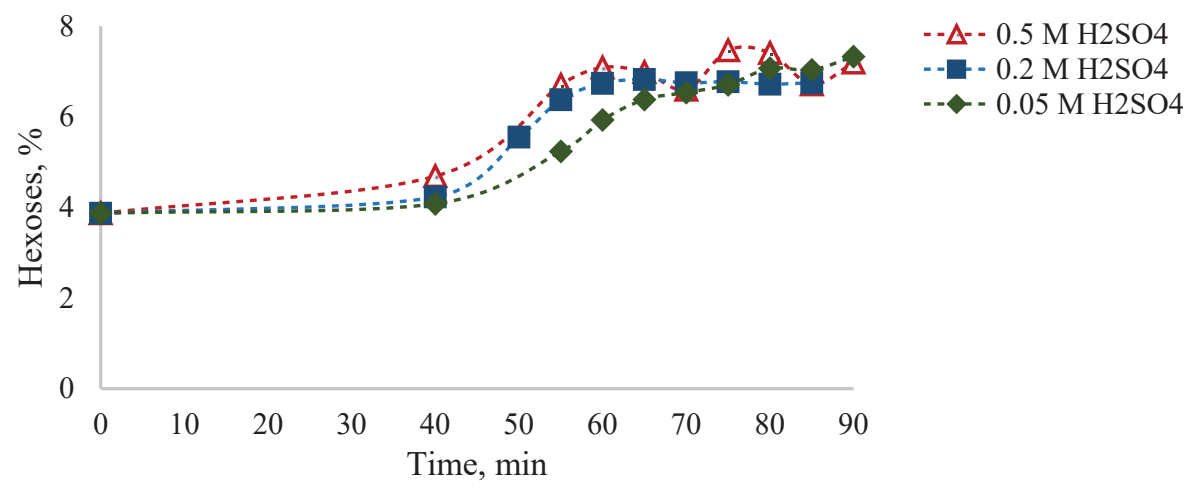

Figure 5. Increase of total hexoses content (\%) in time during acid hydrolysis using different sulfuric acid concentrations at $121^{\circ} \mathrm{C}$.

Table 3

\section{Characteristic parameters of the hydrolyzed pyrolysis liquid sample using different sulfuric acid} concentrations at $131^{\circ} \mathrm{C}$

\begin{tabular}{|c|c|c|c|c|}
\hline Sulfuric acid concentration, $M$ & Total hexoses, $\%$ & Total solids, $\%$ & Aldehydes, $\%$ & Sulfuric acid, $\%$ \\
\hline$-\quad$ (initial sample) & 3.7 & 7.8 & 5.5 & 0.8 \\
\hline 0.1 & 7.5 & 6.4 & 3.5 & 1.5 \\
\hline 0.2 & 7.0 & 7.3 & 5.0 & 2.5 \\
\hline
\end{tabular}




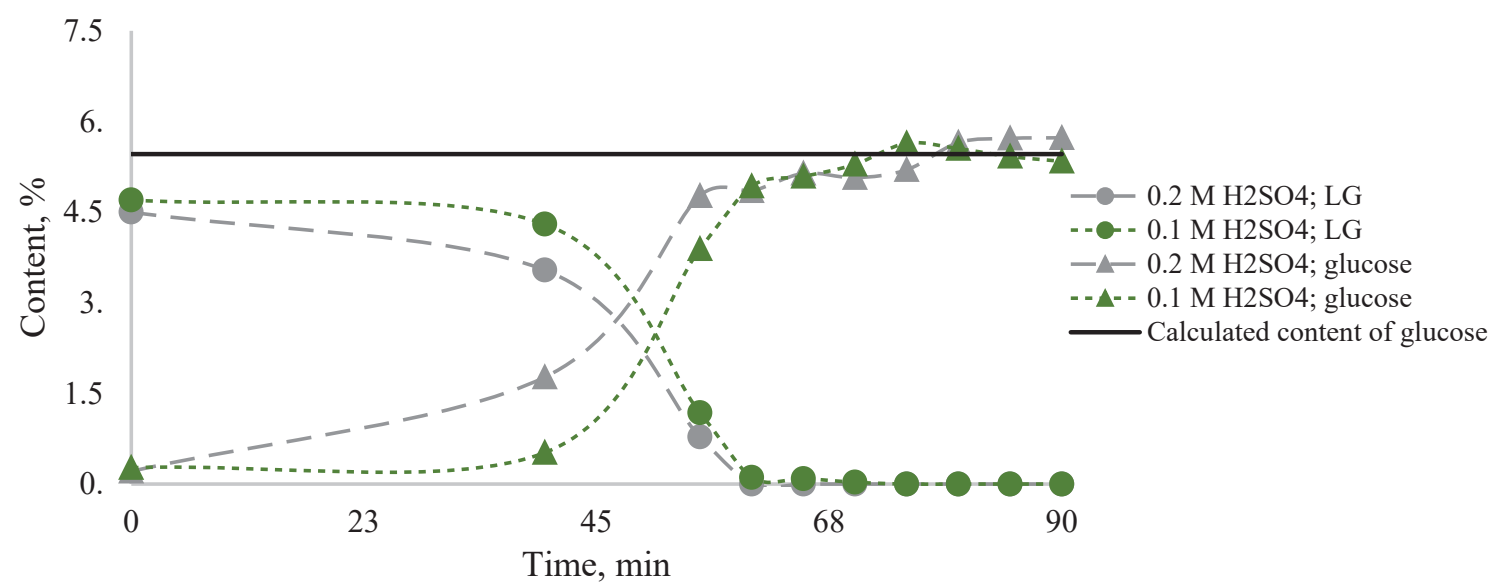

Figure 6. Levoglucosan and glucose content (\%) change in time during acid hydrolysis using different sulfuric acid concentrations at $131{ }^{\circ} \mathrm{C}$.

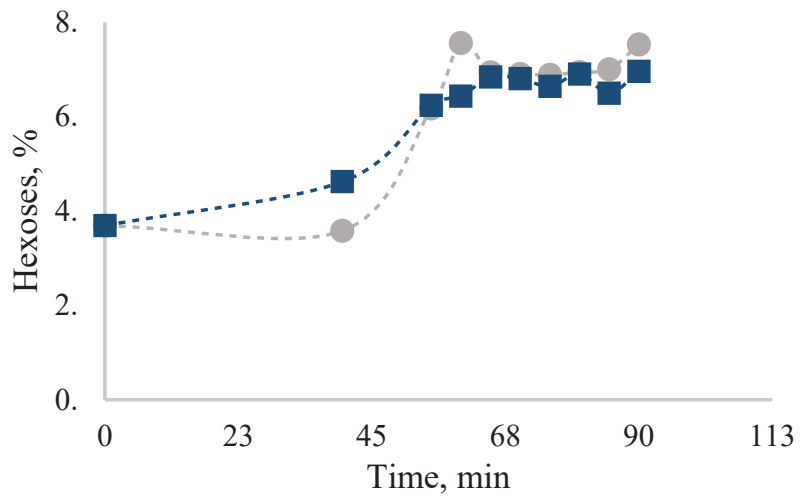

Figure 7. Increase of total hexoses content (\%) in time during acid hydrolysis using different sulfuric acid concentrations at $131^{\circ} \mathrm{C}$.

\section{Conclusions}

1. For the purpose of this study, a method for determining glucose and levoglucosan content in hydrolyzed bio-oil samples were adapted and partially validated in accordance to EuraChem method validation guidelines. All analytical parameters of the obtained method analytical parameters were in acceptable range allowing to conclude that this method is fit for the purpose.

2. Optimal condition for obtaining maximal glucose content from bio-oil samples was $121^{\circ} \mathrm{C}$ with $0.2 \mathrm{M}$ sulfuric acid as a catalyst. Using above mentioned conditions, the total glucose concentration in the sample after hydrolysis was $6.6 \%$ that exceeds calculated glucose amount of $5.5 \%$ meaning in addition to LG there are other sources of glucose being hydrolyzed in these conditions.

3. Obtained results allows us to conclude that by combining fast pyrolysis with acid hydrolysis it is possible to transform lignocellulosic biomass into a form suitable for use in biofuel obtaining.

\section{References}

Aden, A., Ruth, M., Ibsen, K., Jechura, J., Neeves, K., Sheehan, J., Wallace, B., Montague, L., Slayton, A., \& Lukas, J. (2002). National Renewable Energy Laboratory, Golden, CO, NREL/TP-510-32438.

Bennett, N.M., Helle, S.S., \& Duff, S.J. (2009). Extraction and hydrolysis of levoglucosan from pyrolysis oil. Bioresour. Technol. 100(23), 6059-6063. DOI: 10.1016/j.biortech.2009.06.067.

Bridgwater, A.V. (1999). Principles and practice of biomass fast pyrolysis process for liquids. J. Anal. Appl. Pyrolysis. 51(1-2), 3-22. DOI: 10.1016/S0165-2370(99)00005-4.

Czernik, S., \& Bridgwater, A. (2004). Overview of applications of biomass fast pyrolysis oil. Energy Fuels. 18(2), 590-598. DOI: 10.1021/ef034067u. 
Helle, S., Bennett, N.M., Lau, K., Matsui, J.H., \& Duff, S.J. (2007). A kinetic model for production of glucose by hydrolysis of levoglucosan and cellobiosan from pyrolysis oil. Carbohydr. Res. 342(16), 2365-2370. DOI: 10.1016/j.carres.2007.07.016.

Huber, G.W., Chheda, J.N., Barrett, C.J., \& Dumesic, J.A. (2005). Production of liquid alkanes by aqueousphase processing of biomass-derived carbohydrates. Science. 308(5727), 1446-1450. DOI: 10.1126/ science. 1111166.

Huber, G.W., Iborra, S., \& Corma, A. (2006). Synthesis of Transportation Fuels from Biomass: Chemistry, Catalysts, and Engineering. Chem. Rev. 106(9), 4044-4098. DOI: 10.1021/cr068360d.

Isikgor, F.H., \& Becer, C.R. (2015). Lignocellulosic biomass: a sustainable platform for the production of biobased chemicals and polymers. Polym. Chem. 6(25), 4497-4559. DOI: 10.1039/C5PY00263J.

Lian, J., Chen, S., Zhou, S., Wang, Z., O’Fallon, J., Li, C., \& Garcia-Perez, M. (2010). Separation, hydrolysis and fermentation of pyrolytic sugars to produce ethanol and lipids. Bioresour. Technol. 101(24), 96889699. DOI: 10.1016/j.biortech.2010.07.071.

LR Zemkopības ministrija. (2018). Meža Nozare Skaițos un Faktos. Retrieved February 16, 2020, from https:/www.zm.gov.lv/mezi/statiskas-lapas/nozares-informacija/buklets-meza-nozare-skaitlos-un-faktos?nid=1106\#jump.

Magnusson, B., \& Örnemark, U. Eurachem Guide: The Fitness for Purpose of Analytical Methods A Laboratory Guide to Method Validation and Related Topics, (2 $2^{\text {nd }}$ ed. 2014). ISBN 978-91-87461-59-0. Retrieved February 16, 2020, from from http://www.eurachem.org.

Meile, K., \& Zhurinsh, A. (2016). Preparative Solid Phase Extraction for the Purification of Levoglucosan Obtained from Lignocellulose. Key Engineering Materials. 721, 82-86. DOI: 10.4028/www.scientific.net/ KEM.721.82.

Mettler, M.S., Paulsen, A.D., Vlachos, D.G., \& Dauenhauer, P.J. (2012). Pyrolytic conversion of cellulose to fuels: levoglucosan deoxygenation via elimination and cyclization within molten biomass. Energy Environ. Sci. 5(7), 7864-7868. DOI: 10.1039/C2EE21305B.

Mohan, D., Pittman, C.U., \& Steele, P.H. (2006). Pyrolysis of Wood/Biomass for Bio-oil: A Critical Review. Energy Fuels. 20(3), 848-889. DOI: 10.1021/ef0502397.

Mosier, N., Wyman, C., Dale, B., Elander, R., Lee, Y.Y., Holtzapple, M., \& Ladisch, M. (2005). Features of promising technologies for pretreatment of lignocellulosic biomass. Bioresour. Technol. 96(6), 673-686. DOI: 10.1016/j.biortech.2004.06.025.

Oasmaa, A., \& Czernik, S. (1999). Fuel oil quality of biomass pyrolysis oils state of the art for the end users. Energy Fuels. 13(4), 914-921. DOI: 10.1021/ef980272b.

Ragauskas, A.J., Williams, C.K., Davison, B.H., Britovsek, G., Cairney, J., Eckert, C.A., Frederick, W.J. Jr, Hallett, J.P., Leak, D.J., Liotta, C.L., Mielenz, J.R., Murphy, R., Templer R., \& Tschaplinski, T. (2006). The path forward for biofuels and biomaterials. Science. 311(5760), 484-489. DOI: 10.1126/science.1114736.

Sipilä, K., Kuoppala, E., Fagernäs, L., \& Oasmaa, A. (1998). Characterization of biomass-based flash pyrolysis oils. Biomass Bioenergy. 14(2), 103-113. DOI: 10.1016/S0961-9534(97)10024-1.

Schuler, J., Hornung, U., Dahmen, N., \& Sauer, J. (2019). Lignin from Bark as a Resource for Aromatics Production by Hydrothermal Liquefaction. GCB Bioenergy. 11 (1), 218-229. DOI: 10.1111/gcbb.12562. 